\title{
ZAMAN BAĞIMLI ARAÇ ROTALAMA PROBLEMİ İÇİN BİR MATEMATİKSEL MODEL
}

\author{
Çağrı KOÇ*, İsmail KARAOĞLAN ${ }^{* *}$ \\ *Southampton Management School and Centre for Operational Research, Management Science and Information \\ Systems (CORMSIS), University of Southampton, Southampton, United Kingdom \\ **Selçuk Üniversitesi, Endüstri Mühendisliği Bölümü, Selçuklu, Konya \\ c.koc@soton.ac.uk, ikaraoglan@selcuk.edu.tr
}

(Geliş/Received: 01.10.2013; Kabul/Accepted: 22.05.2014)

\section{ÖZET}

Bu çalışmada klasik Araç Rotalama Problemi'nin (ARP) genelleştirilmiş bir çeşidi olan Zaman Bağımlı Araç Rotalama Problemi (ZBARP) ele alınmıştır. ZBARP, ARP'den farklı olarak, araç hızının düğümler arasında değişken olduğu durumlarda araç filosunun rotalanması olarak tanımlanmaktadır. ZBARP için literatürdeki modellerden farklı bir şekilde ilk olarak, "ilk giren ilk çıkar (FIFO)" özelliğini sağlayan, zamana bağlı hız fonksiyonunu göz önüne alan ve doğrusal yapıya sahip yeni bir karma tam sayılı matematiksel model geliştirilmiştir. Literatürden türetilen test problemleri üzerindeki deneysel çalışmalar sunulmuş ve modelin performansı en iyi çözüme ulaşma zamanı ve en iyi çözümden yüzde sapma değeri açısından değerlendirilmiştir. Çeşitli parametrelerin değişmesinin modelin performansı üzerindeki etkisinin anlaşılması için 3 farklı senaryo analizi oluşturulmuştur.

Anahtar kelimeler: Araç Rotalama Problemi, Matematiksel Model, Zaman Bağımlı Seyahat Hızı.

\section{A MATHEMATICAL MODEL FOR THE TIME-DEPENDENT VEHICLE ROUTING PROBLEM}

\begin{abstract}
In this study, the Time-Dependent Vehicle Routing Problem (TDVRP) is considered which is a generalized version of the classical Vehicle Routing Problem (VRP). Unlike the VRP, the TDVRP can be defined as the routing a fleet of vehicle in which vehicle speeds are variable between the nodes. For the first time in literature, a new mathematical model, based on linear function, is developed for the TDVRP which considers the timedependent speed function that satisfies the "first-in-first-out" (FIFO) property and differs from the existing models in literature. Computational results on a large set of instances, generated from literature, are presented and the performance of the model evaluated in terms of computation time and percentage deviations to optimal solution. Three scenario analyses are conducted to assess the effect of changing several parameters on the model performance.
\end{abstract}

Keywords: Vehicle Routing Problem, Mathematical Model, Time-Dependent Travel Speed

\section{GIRISŞ (INTRODUCTION)}

Araç Rotalama Problemi (ARP) bütün müşterilerin ihtiyacını karşılayan en küçük maliyetli rotaların belirlenmesi problemidir. ARP sahip olduğu kıstlara göre farklı türlere sahiptir ve NP-zor problem sinıfinda yer almaktadır $[1,2,3]$. Her geçen gün önemi biraz daha artan taşımacılık sistemlerinin önemli bir bileşeni olan ARP, ele alındığı ilk günden bu yana üzerinde çeșitli çalıșmaların yapılldığı bir problem tipi olmuştur [4,5]. Fiziksel üretimin gerçekleştiği bütün sektörlerde (otomotiv, gıda, tekstil vb.) ve hizmet sektörünün değişik alanlarında (kargo taşımacılığı vb.) karşılaşılan bu problem için yapılan çalışmaların çok büyük bir kısmında düğümler (depolar ve müşteriler) arası ulaşım süresinin sabit alındığı görülmektedir. 
Zaman Bağımlı Araç Rotalama Problemi'nde (ZBARP) düğümler arası ulaşım sürelerinin gün içerisinde değiştiği durum ele alınmaktadır. Bu bağlamda, planlama periyodu (örneğin bir gün) zaman aralıklarına bölünerek bu zaman aralıklarında her bir yol için sabit bir hız tanımlanmaktadır. Bir düğümden çıkan araç çıkış zamanına ve kullanacağı yola bağlı olarak belli bir hız ile bir sonraki düğüme seyahat etmektedir. Eğer sıradaki düğüme seyahat esnasında bir sonraki zaman dilimine geçiş olursa, araç yeni zaman dilimi için tanımlanmış olan hız ile yoluna devam edecektir. $\mathrm{Bu}$ varsayım pratikte karşılaşılan durumlara oldukça benzerlik göstermektedir. Örneğin, gün içerisinde, iş merkezlerinin yoğunlukta olduğu bölgelere giren/çıkan yollarda sabah mesai başlangıcında (07.00-09.00), öğle mola saatlerinde (12.00-13.00) ve akşam iş çıkış saatlerinde (17.0019.00) yüksek trafik yoğunluğu (düşük araç hızları) diğer zaman aralıklarında ise düşük trafik yoğunluğu (yüksek araç hızları) söz konusudur.

ARP üzerinde çok fazla çalışma yapılmış olup detaylı bilgi için Cordeau vd. [6] tarafından yapılan literatür taramas1, Toth ve Vigo [1], Golden vd. [7] tarafindan yazılan, ARP için geliştirilen modelleri ve algoritmaların açıklandığı kitaplar incelenebilir.

Zaman bağımlı ulaşım süreleri ilk kez Malandraki ve Daskin [8] tarafından, ZBARP ve Zaman Bağıml Gezgin Satıcı Problemi (ZBGSP) üzerinde ele alınmıştır. Bu çalışmada, "Zamana Bağlı Adımsal Ulaşım Süresi Fonksiyonu; ZBAUSF” kullanılmıştır. Problemlerin çözümü için matematiksel model, dalkesme algoritması ve açgözlü sezgiseli önerilmiş ve düğüm sayısının 10 ile 25 arasında değiştiği test problemleri çözülmüştür. Ahn ve Shin [9], çalışmalarında Zaman Pencereli ZBARP (ZPZBARP) için kazanç, başlangıç ve yerel iyileştirme algoritmalarını kullanmışlardır. Hill ve Benton [10] tarafindan yapılan bir çalışmada ise aracın bir düğümden çıkış zamanına bağlı olarak ulaşım süresi yerine hız değeri kullanılmıştır. Malandraki ve Dial [11], ZBGSP için dinamik programlama yaklaşımı geliştirmişlerdir. Park [12], iki kriterli zaman ve alan bağımlı seyahat süreli araç çizelgeleme problemini göz önüne almıştır. Jung ve Haghani [13], ZBARP için bir matematiksel model formülasyonu ve bir Genetik Algoritma (GA) önermişlerdir.

Literatürde, ZBARP için yapılmış çalışmaların büyük bir kısmında ZBAUSF kullanılmıştır. ZBAUSF'de gerçekçi olmayan bir yaklaşım olan aracın yolu daha kısa sürede kullanacağı zamana kadar müşteride beklemesi varsayımı dikkate alınmaktadır. Bu durum Şekil 1 ve Şekil 2'de örnek üzerinde anlatılmaktadır. $\mathrm{Bu}$ şekillerde bir düğümden çıkan aracın çıkış zamanına göre bir sonraki düğüme ulaşım süresini göstermektedir. Buna göre, 4. zaman biriminde çıkış yapan bir araç bir sonraki düğüme 8 . zaman biriminde ulaşacaktır. Ancak 6. zaman biriminde çıkan başka bir araç ise 7 . zaman biriminde bir sonraki düğüme ulaşacaktır. Yani bu duruma göre aracın önce çıkış yapması hedefe daha geç ulaşmasına neden olacaktır ki bu durum pratikte karşılaşılan duruma tamamen aykırıdır.

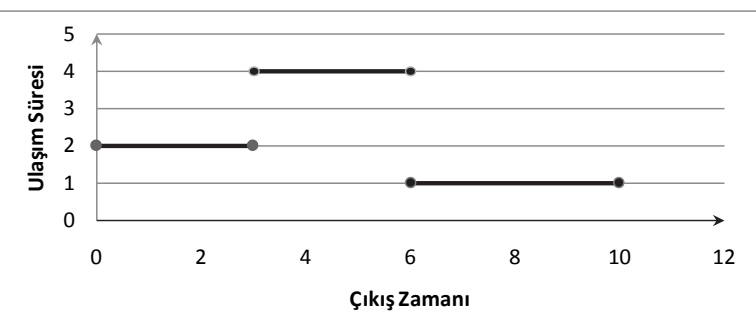

Şekil 1. Çıkış zamanına bağlı ulaşım süreleri (Departure time based travel times).

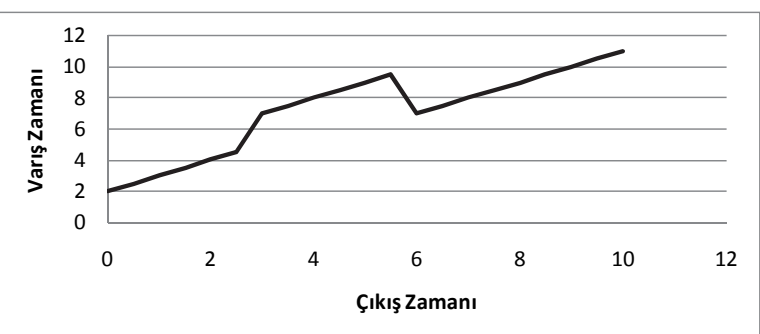

Şekil 2. Çıkış zamanına bağlı ulaşım sürelerine göre varış zamanları (Arrival times in which departure time is based on the travel times).

Literatürde FIFO “ilk giren ilk çıkar” özelliği olarak adlandırılan yukarıdaki durumu sağlamak amacıyla iki yaklaşım geliştirilmiştir. Bunlar;

1. Aracın daha erken gidebileceği bir sonraki zaman dilimine kadar müsteride bekletilmesi: Şekil 1'deki örnekte 4. zaman biriminde çıkış yapmaya hazır olan aracin 6. zaman birimine kadar bekletilmesi bu yaklaşıma örnek olarak verilebilir. İşini bitiren aracın müşteride bekletilmesinin söz konusu olmadiğ pratikte de karşılaşılmayan bir durum olduğu için bu yaklaşım birçok araştırmacı tarafindan eleştirilmektedir (örneğin $[12,13,14,15]$ ).

2. FIFO özelliğini sağlayacak düzeltme fonksiyonlarının geliștirilmesi: $\mathrm{Bu}$ yaklaşımda ulaşım süresi fonksiyonunun adımsal yapısı parçalı doğrusal yapıya dönüştürülmektedir. $\mathrm{Bu}$ dönüşüme göre, ardışık zaman dilimleri arasındaki geçiş noktalarının $\pm \Delta$ genişliğinde kalan bölüm için $\alpha+\beta t$ düzeltmesi yapılmaktadır ki fonksiyonun FIFO özelliğini sağlaması için $\beta \geq-1$ olması gerekmektedir [14]. Şekil 3'de bu yaklaşım örnek üzerinde gösterilmektedir. Bu yaklaşımda, ulaşım sürelerinin gerçek değerleri yerine yaklaşık değerlerini vereceği için sonuçta ya yerel en iyi ya da uygun olmayan çözümlere ulaşılma riski ile karşılaşılmaktadır. Ayrıca her zaman $\beta \geq \mathbf{- 1}$ şartını sağlayacak fonksiyonlarla karşılaşamama ihtimali de bulunmaktadır (örneğin zaman aralıklarının dar ve ulaşım süreleri arasındaki farkın büyük olması gibi). 


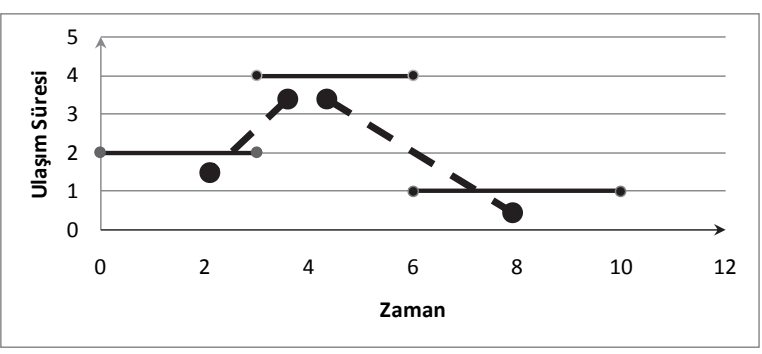

Şekil 3. FIFO özelliği olmayan ulaşım sürelerine düzeltme fonksiyonu uygulaması (Application of the correction function to the travel times without FIFO property).

Literatürde, Ichoua vd. [15] tarafından yapılan çalışmaya kadar ZBARP'de yapılan çalışmaların hemen hemen tamamında ZBAUSF kullanılmış ve FIFO özelliği yukarıda bahsedilen iki durum göz önüne alınarak sağlanmaya çalışılmıştır. FIFO özelliğini en iyi şekilde sağlayan ve pratiğe oldukça yakın bir varsayım olan Zamana Bağlı Hız Fonksiyonu (ZBHF) yaklaşımı ise ilk kez Ichoua vd. [15] tarafından önerilmiştir. $\mathrm{Bu}$ yaklaşıma göre planlama periyodu ZBAUSF yaklaşımında olduğu gibi zaman dilimlerine bölünmekte ve her düğüm için aracın çıkış zamanına bağlı olarak adımsal bir hız fonksiyonu tanımlanmaktadır. Bu yaklaşım Şekil 4 ve 5 'de örnek üzerinde anlatılmaktadır.

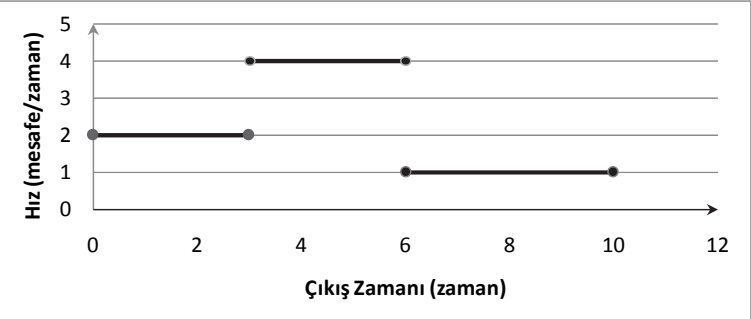

Şekil 4. Çıkış zamanına bağlı hız (Departure time based speed).

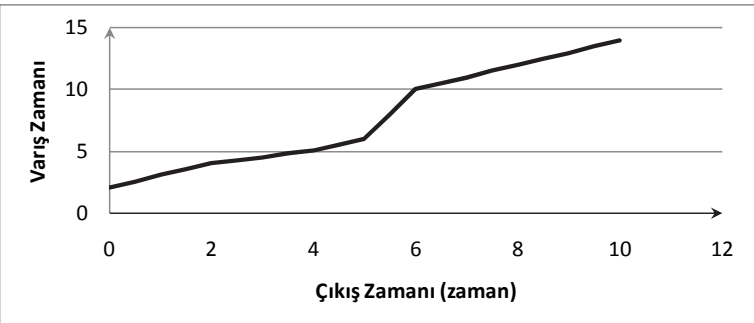

Şekil 5. Çıkış zamanına bağlı hıza göre varış süreleri (Arrival times based on departure time).

Şekil 4'de düğümler arası mesafenin 4 birim olduğu bir hat için çıkış zamanına bağlı hızlar, Şekil 5'de ise bu hızlara bağlı olarak bir sonraki düğüme varış zamanı gösterilmektedir. Bu şekillerden de görüldüğü gibi çıkış zamanı ne olursa olsun araç bir düğümden ne kadar erken çıkarsa bir sonraki düğüme o kadar erken ulaşmaktadır. Ichoua vd. [15] bu çalışmalarında gevşek zaman pencereli ZBARP'yi ele almış ve problemin çözümü için bir Tabu Arama (TA) sezgiseli geliştirmişlerdir.
Fleischmann vd. [16] tarafından yapılan bir çalışmada ise yine ZBAUSF kullanılmış ve FIFO özelliğini sağlamak amaciyla fonksiyon üzerinde düzeltme işlemleri gerçekleştirilmiştir. Haghani ve Jung [17] aynı problem için bir GA önermişlerdir. Chen vd. [18] Gerçek Zamanlı ZBARP'ni (bazı çalışmalarda aynı problem Dinamik ARP olarak da tanımlanmaktadır) ele almışlardır. Woensel vd. [19], trafik sıkışıklığını göz önüne alan kuyruk teorisine dayalı bir sezgisel yaklaşım geliştirmişlerdir. Bir sonraki çalışmalarında Woensel vd. [20] zaman bağımlı seyahat süreli ve Kapasiteli ARP'yi çözmek için bir TA algoritması geliştirmişlerdir.

Hashimoto vd. [21] tarafından yapılan bir çalışmada ise ZBHF yaklaşımının kullanıldığı Zaman Pencereli ZBARP için doğrusal olmayan bir matematiksel model ve yinelemeli yerel arama yöntemi geliştirilmiştir. Kuo vd. [22], ZBHF yaklaşımının kullanıldığı ZBARP'ni ele almış ve problemin çözümü için TA algoritması geliştirmişlerdir. Soler vd. [23], çalışmalarında ZPZBARP'yi değişik dönüşüm teknikleri ile Asimetrik ARP'ne dönüştürmüş ve bilinen çözüm yöntemleri ile çözülebileceğine değinmişlerdir.

Literatürde son yıllarda yapılan çalışmalar incelendiğinde, Karınca Kolonisi (KK) algoritmasının, ARP'nin diğer tiplerinde olduğu gibi ZBARP'de de başarıyla uygulandığ görülmektedir [14, 24]. Donati vd. [24], ZBHF yaklaşımının kullanıldığı ZBARP ve ZPZBARP problemini ele almışlardır. Jabali vd. [25], stokastik ZBARP'yi ele aldıkları çalışmalarında ZBHF yaklaşımını kullanarak müşterilerde beklenmedik gecikmeleri ele almışlar ve problemin çözümü için TA sezgiseli önermişlerdir.

Kuo [26], ZBARP'de harcanan yakıtın enazlanması için Tavlama Benzetimi (TB) algoritması geliştirmiştir. Figliozzi'nin [27] yaptığ1 çalışmada ZBARP'de $\mathrm{CO}_{2}$ salınımını analiz eden bir matematiksel model önerilmiştir. Liu vd. [28], ZBARP için matematiksel modeller önermişler ve geleneksel KK algoritmasını geliştirmişlerdir. Balseiro vd. [14], ZBHF yaklaşımında düzeltme fonksiyonunun kullanıldığı ZPZBARP'yi ele almış ve problemlerin çözümü için bir matematiksel model önermişlerdir. Donati vd. [24] tarafindan kullanılan çoklu koloni yapısını kullanılmıştır. Önerilen matematiksel model ZBHF yaklaşımını tam manası ile yansitmamaktadır. Bu matematiksel model ile ilgili herhangi bir deneysel karşılaştırmaya da rastlanmamıştır.

Yapılan literatür taraması sonucunda, FIFO özelliğini en iyi şekilde sağlayan ZBHF yaklaşımının kullanıldığ 1 çalışmaların hemen hemen tamamında sezgisel yöntemler üzerinde yoğunlaşıldığı görülmektedir. $\mathrm{Bu}$ çalışmalarda geliştirilen matematiksel modeller de doğrusal olmayan bir 
yapıya sahiptir ki bu modellerle çok küçük boyutlu problemler bile çok uzun sürelerde çözülebilmektedir. $\mathrm{Bu}$ çalışmanın amacı, ZBARP için literatürdeki modellerden farklı bir şekilde ilk olarak "ilk giren ilk çıkan" (FIFO) özelliğini sağlayan zamana bağlı hız fonksiyonunu göz önüne alan, kesin hesaplama gerçekleştiren ve doğrusal yapıya sahip karma tam sayılı bir matematiksel model geliştirmek ve literatürden türetilen test problemleri ile önerilen modeli test etmektir.

Çalışmanın bundan sonraki kısmı şu şekilde düzenlenmiştir. İkinci bölümünde problem tanımı ve önerilen karma tam sayılı matematiksel model, üçüncü bölümde deneysel sonuçlar ve izleyen bölümde ise bu çalışmadan elde edilen sonuçlar sunulmuştur.

\section{PROBLEM TANIMI VE MATEMATIKSEL MODEL (PROBLEM DEFINITION and MATHEMATICAL MODEL)}

ZBARP notasyonel olarak şu şekilde tanımlanabilir: $G=(N, A)$ tam bağlı bir şebeke olsun, $N$ tüm düğümlerin kümesini $\left(N=0 \cup N_{c}\right), \quad$ "0" depo düğümünü, $N_{c}$ müşteri kümesini, $A$ düğümler arasındaki hatları tanımlamaktadır.

ZBARP tanımlanan bu şebeke üzerinde aşağıdaki varsayımlar altında en düşük maliyetli rotaların tespiti problemidir:

(i) her müşteriye kesinlikle bir kez uğranmal,,

(ii) bir rota depodan başlamalı ve tekrar depoda son bulmalı,

(iii) rota üzerindeki müşterilerin talepleri toplamı araç kapasitesini geçmemeli,

(iv) her müşteriye girişler ve çıkışlar zaman dilimleri içerisinde gerçekleşmeli,

(v) iki düğüm arasındaki ulaşım süresi, aracın düğümden çıkış zamanına ve düğümler arasındaki uzaklığa bağımlı olmalıdır.

Önerilen matematiksel modelde kullanılan problem girdileri ve değişkenler aşağıda verilmiştir.

\section{Problem Girdileri}

$Q$ : araç kapasitesi.

$K$ : zaman dilimi kümesi $(\forall k, l \in K)$.

$M_{i j}$ : büyük bir sayı.

$q_{i}: i$ düğümünün talebi $\left(\forall i \in N_{c}\right)$.

$d_{i j}: i$ düğümü ile $j$ düğümü arasındaki uzaklık $(\forall i, j \in N)$.

$L B_{k}: k$ diliminin başladığ zaman $(\forall k \in K)$.

$U B_{k}: k$ diliminin bittiği zaman $(\forall k \in K)$.

$v_{k i j}: k$ dilimi içerisinde $i$ düğümünden $j$ düğümüne seyahat hızı $(\forall i, j \in N ; \forall k \in K)$.

$s_{i}: i$ müşterisinin servis süresi $\left(\forall i \in N_{c}\right)$.

\section{İkili Karar Değisskenleri}

$x_{i j}$ : eğer araç $i$ düğümünden $j$ düğümüne geçiyorsa 1 $(\forall i, j \in N)$, diğer durumlarda 0 .

$y_{i j k l}$ : eğer araç $i$ düğümünden $\mathrm{k}$ zaman diliminde çıkıp $j$ düğümüne $l$ zaman diliminde varıyorsa 1 $(\forall i, j \in N ; \forall k, l \in K ; l \geq k)$, diğer durumlarda 0 .

\section{Ek Karar Değișkenleri}

$u_{i}: i$ müşterisine girmeden hemen önce araç üzerindeki dağıtılacak ürün miktarı $\left(\forall i \in N_{c}\right)$.

$T_{i}^{+}$: aracın $i$ müşterisine giriş zamanı $\left(\forall i \in N_{c}\right)$.

$T_{i}^{-}$: aracın $i$ düğümünden çıkış zamanı $(\forall i \in N)$.

$\mathrm{TO}_{i}^{+}$: eğer araç $i$ müşterisinden depoya dönüş yapıyorsa, aracın depoya dönüş zamanı, aksi halde " 0 " $\left(\forall i \in N_{c}\right)$.

$T T_{i j}: i$ düğümünden $j$ düğümüne geçiş süresi $(\forall i, j \in$ $N)$.

Önerilen matematiksel model aşağıda sunulmaktadır:

Amac Fonksiyonu

En küçük $Z=\sum_{i, j \in N} T T_{i j}$

$\underline{\text { Kisitlar }}$

$\overline{\sum_{i \in N} x_{i j}}=1 \quad\left(\forall j \in N_{c}\right)$

$\sum_{j \in N} x_{i j}=\sum_{j \in N} x_{j i} \quad(\forall i \in N)$

$\sum_{k \in K} \sum_{l \in K} y_{i j k l}=x_{i j} \quad(\forall i, j \in N ; l \geq k)$

$u_{j}-u_{i}+Q x_{i j}+\left(Q-q_{i}-q_{j}\right) x_{j i} \leq Q-q_{i}$

$\left(\forall i, j \in N_{c} ; i \neq j\right)$

$u_{i} \geq q_{i}+\sum_{j \in N_{c}, j \neq i} q_{j} x_{i j} \quad\left(\forall i \in N_{c}\right)$

$u_{i} \leq Q-\left(Q-q_{i}\right) x_{i 0} \quad\left(\forall i \in N_{c}\right)$

$T T_{i j} \leq T_{j}^{+}-T_{i}^{-}+M_{i j}\left(1-x_{i j}\right)$

$\left(\forall i \in N, \forall j \in N_{c}\right)$

$T T_{i j} \geq T_{j}^{+}-T_{i}^{-}+M_{i j}\left(x_{i j}-1\right)$

$\left(\forall i \in N, \forall j \in N_{c}\right)$

$T T_{j 0} \leq T O_{j}^{+}-T_{j}^{-}+M_{j 0}\left(1-x_{j 0}\right) \quad\left(\forall j \in N_{c}\right)$

$T T_{j 0} \geq T O_{j}^{+}-T_{j}^{-}+M_{j 0}\left(x_{j 0}-1\right) \quad\left(\forall j \in N_{c}\right)$

$d_{i j}-M\left(2-x_{i j}-y_{i j k k}\right) \leq\left(T_{j}^{+}-T_{i}^{-}\right) v_{k i j}$

$\left(\forall i \in N, \forall j \in N_{c}\right),(\forall k \in K)$

$d_{i j}-M\left(2-x_{i j}-y_{i j k l}\right) \leq\left(U B_{k}-T_{i}^{-}\right) v_{k i j}+$ $\sum_{k<m<l}\left(U B_{m}-L B_{m}\right) v_{m i j}+$

$$
\left(T_{j}^{+}-L B_{l}\right) v_{l i j}
$$

$\left(\forall i \in N, \forall j \in N_{c}\right),(\forall k, l \in K), l>k$

$d_{j 0}-M\left(2-x_{j 0}-y_{j 0 k k}\right) \leq\left(T O_{j}^{+}-T_{j}^{-}\right) v_{k j 0}$

$\left(\forall j \in N_{c}\right),(\forall k \in K)$

$d_{j 0}-M\left(2-x_{j 0}-y_{j 0 k l}\right) \leq\left(U B_{k}-T_{j}^{-}\right) v_{k j 0}+$ $\sum_{k<m<l}\left(U B_{m}-L B_{m}\right) v_{m j 0}+$ $\left(T O_{j}^{+}-L B_{l}\right) v_{l j 0}$

$\left(\forall j \in N_{c}\right),(\forall k, l \in K), l>k$

$\sum_{j \in N} \sum_{k, l \in K} y_{i j k l} U B_{k} \geq T_{i}^{-} \quad\left(\forall i \in N_{c}\right)$

$\sum_{j \in N} \sum_{k, l \in K} y_{i j k l} L B_{k} \leq T_{i}^{-} \quad\left(\forall i \in N_{c}\right)$

$\sum_{j \in N} \sum_{k, l \in K} y_{j i k l} U B_{l} \geq T_{i}^{+} \quad\left(\forall i \in N_{c}\right)$

$\sum_{j \in N} \sum_{k, l \in K} y_{j i k l} L B_{l} \leq T_{i}^{+} \quad\left(\forall i \in N_{c}\right)$

$\sum_{j \in N} \sum_{k, l \in K} y_{i 0 k l} U B_{l} \geq T O_{i}^{+} \quad\left(\forall i \in N_{c}\right)$

$\sum_{j \in N} \sum_{k, l \in K} y_{i 0 k l} L B_{l} \leq T O_{i}^{+} \quad\left(\forall i \in N_{c}\right)$

$T_{i}^{-}=T_{i}^{+}+s_{i} \quad\left(\forall i \in N_{c}\right)$ 
$x_{i j} \in\{0,1\} \quad(\forall i, j \in N)$

$y_{i j k l} \in\{0,1\} \quad(\forall i, j \in N),(\forall k, l \in K)$

$u_{i}, T_{i}^{+}, T_{i}^{-}, T O_{i}^{+} \geq 0 \quad\left(\forall i \in N_{c}\right)$

$T T_{i j} \geq 0 \quad(\forall i, j \in N)$.

Burada $\quad M_{i j}=\max _{\forall i \in N}\left(U B_{i}\right)$ almak yeterlidir. Ayrıca, çözüme başlamadan önce bütün ayrıtlar için $y_{i j k l}=0: \forall i, j \in N ; l<k$ ataması gerçekleştirilmektedir. $\mathrm{Bu}$ atama, aracın bir düğümden diğerine sonraki zaman dilimlerinden birisinden başlayıp önceki zaman dilimlerinden birisinde geçmesini engellemektedir.

Matematiksel modelde (1) numaralı amaç fonksiyonu, toplam rota süresini enazlamaktadır. (2) ve (3) numaralı kısıtlar ARP için geliştirilmiş genel atama kısıtlarıdır ve bir müşteriye mutlaka bir kere hizmet verilmesini garantilemekte, buna ek olarak düğümlerin girdi çıktı dengesini sağlamaktadır. (4) numaralı kısıtlar her hat için, eğer hat kullanılıyorsa aracın seyahate mutlaka bir zaman diliminde başlayıp aynı ya da farklı bir zaman diliminde bitirmesini garantilemektedir.

(5) ve (7) numaralı kisitlar MTZ (Miller-TuckerZemlin) kapasite ve alt tur eleme kisitlarıdır. (5) numaralı kısıt bir rota üzerinde dağıtım taleplerinin toplamlarının kapasiteyi geçmemesini sağlamakla beraber alt turların oluşmasını da engellemektedir. (6) ve (7) numaralı kısıtlar yardımcı karar değişkenlerinin alt ve üst sınırlarını belirleyen kısıtlardır.

(8-11) numaralı kısıtlar düğümlere giriş ve çıkış zamanlarının, düğümler arası geçiş süreleri ile bağlantılı olmasını sağlamaktadır. (8) ve (9) numaralı kısıtlar tüm düğümlerden müşterilere giriş, (10) ve (11) numaralı kısıtlar ise müşteriden depoya dönüş sürelerini belirleyen kısıtlardır.

(12-15) numaralı kısıtlar, zaman dilimleri arasındaki geçişlerin araç hızıyla ve kat edilen mesafeyle bağlantılı olmasını sağlamaktadır. Burada tanımlanan ulaşım süresi hesaplama tekniği sadece ardışık zaman dilimleri (yani $l=k+1$ ) için değil, ardışık olmayan zaman dilimleri (yani $l \geq k+1$ ) için de geçerlidir. (12) numaralı kısıt aracın $k$ zaman diliminde çıkıp aynı zaman diliminde bir sonraki müşteriye girişini, (13) numaralı kısıt ise aracın $k$ zaman diliminde çıkıp daha büyük bir $l$ zaman diliminde bir sonraki müşteriye girişini sağlamaktadır. (14) numaralı kısıt aracın $k$ zaman diliminde müşteriden çıkıp aynı zaman diliminde depoya dönüşünü, (15) numaralı kısıt ise aracın $k$ zaman diliminde müşteriden çıkıp daha büyük bir $l$ zaman diliminde depoya dönüşünü sağlamaktadır.

(16) ve (19) numaralı kisitlar zaman dilimlerinin alt ve üst sınırlarının, aracın müşterilerden tüm düğümlere giriş ve çıkış zamanlarıyla bağlantılı olmasinı, (20) ve (21) numaralı kisitlar ise zaman dilimlerinin alt ve üst sınırlarının aracın müşteriden depoya dönüşü ile bağlantılı olmasını sağlamaktadır.

(22) numaralı kısıt, aracın müşteriden çıkış zamanının, müşteriye giriş zamanı ile müşteride geçirdiği servis zamanının toplamına eşit olmasını garantilemektedir. (23-26) numaralı kısıtlar ise işaret kisitlarıdır.

ZBARP için önerilen matematiksel model $O\left(|N|^{2}|K|^{2}\right)$ karmaşıklığında $\{0,1\}$ karar değişkeni, $O\left(|N|^{2}\right)$ karmaşıklığında ek karar değişkeni ve $O\left(|N|^{2}|K|^{2}\right)$ karmaşıklığında kısıta sahiptir.

Geliştirilen karma tam sayılı matematiksel modelde, aracın düğümler arasındaki geçişlerini zaman bağımlılı̆̆ kavramı ile bağlantılı olarak sağlamak için önerilen (12) ve (13) numaralı kısıtların geçerliliği aşağıda Önerme 1 ve Önerme 2 ile ispatlanmaktadır.

Önerme 1: (12) numaralı kisıt ZBHF yaklaşımı altında ZBARP için geçerli bir kısıttır.

İspat: Bir araç $i$ düğümünden $j$ düğümüne geçiyorsa $x_{i j}=1$ ve $i$ düğümünden $k$. zaman diliminde çıkıp $j$ düğümüne $k$. zaman diliminde varıyorsa (4) numaralı kısıttan dolayı $y_{i j k k}=1$ değerlerini alır. Bu durumda (12) numarali kisit

$d_{i j} \leq\left(T_{j}^{+}-T_{i}^{-}\right) v_{k i j} \quad\left(\forall i \in N, \forall j \in N_{c}\right)$

şekline dönüşür. Ayrıca (4) numaralı kısıttan dolayı diğer bütün $y_{i j k l}$ değerleri " 0 ” ve (13) numaralı kısıtın sol tarafı negatif değer alacağından dolayı (13) numaralı kısıt anlamsız hale gelecektir. Dolayısıyla (12) numaralı kısıt, aracın $i$ düğümünden çıkışı ile $j$ düğümüne girişinin aynı zaman dilimi içerisinde gerçekleştirildiği durum için geçerli bir kısıttır.

Önerme 2: (13) numaralı kisıt ZBHF yaklaşımı altında ZBARP için geçerli bir kisıttır.

Ispat: Bir araç $i$ düğümünden $j$ düğümüne geçiyorsa $x_{i j}=1$ ve $i$ düğümünden $k$. zaman diliminde çıkıp $j$ düğümüne $l$. zaman diliminde varıyorsa (4) numaralı kısıttan dolayı $y_{i j k l}=1$ değerlerini alır. Bu durumda (13) numaralı kisit

$d_{i j} \leq\left(U B_{k}-T_{i}^{-}\right) v_{k i j}+\sum_{k<m<l}\left(U B_{m}-\right.$
$\left.L B_{m}\right) v_{m i j}+\left(T_{j}^{+}-L B_{l}\right) v_{l i j} \quad\left(\forall i \in N, \forall j \in N_{c}\right)$

şekline dönüşür. Ayrıca (4) numaralı kısıttan dolayı diğer bütün $y_{i j k k}$ değerleri " 0 " ve (8) numaralı kısıtın sol tarafı negatif değer alacağından dolayı (12) numaralı kısıt anlamsız hale gelecektir. Dolayısıyla (13) numaralı kısıt, aracın $i$ dügüumünden çıkışı ile $j$ düğümüne girişinin farklı zaman dilimi içerisinde gerçekleştirildiği durum için geçerli bir kısıttır. Şekil 6'da bu durum, düğümlere giriş ve çıkış zamanlarının örnek gösterimi ile sunulmuştur. 


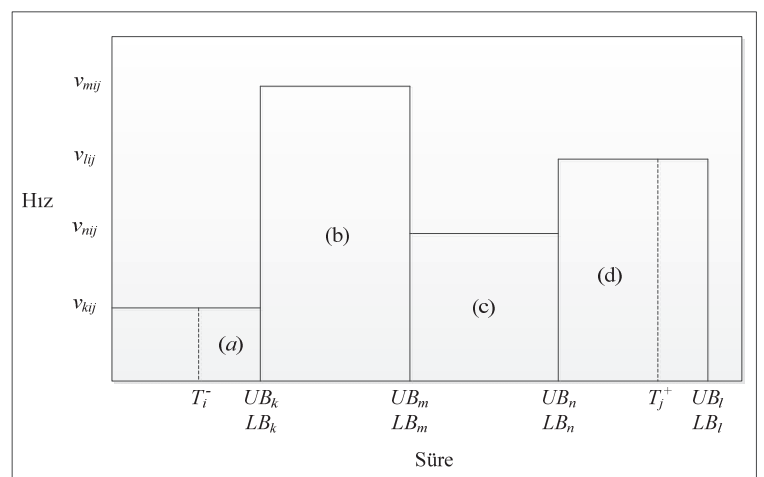

Şekil 6. Düğümlere giriş ve çıkış zamanlarının örnek gösterimi (Illustration of arrival and departure times to the nodes).

Şekil 6'da sunulan örnek göz önüne alındığında, (a), (b), (c) ve (d) bölgelerinde kat edilen mesafeler aşağıdaki formülasyonlar ile hesaplanmaktadır.

(a): bölgesinde aracın kat ettiği mesafe: $\left(U B_{k}-\right.$

$\left.T_{i}^{-}\right) v_{k i j}$

(b): bölgesinde aracın kat ettiği mesafe: $\left(U B_{m}-\right.$ $\left.L B_{m}\right) v_{m i j}$

(c): bölgesinde aracın kat ettiği mesafe: $\left(U B_{n}-\right.$

$\left.L B_{n}\right) v_{n i j}$

(d): bölgesinde aracın kat ettiği mesafe: $\left(T_{j}^{+}-L B_{l}\right) v_{l i j}$

Aracın $\forall i \in N, j \in N_{c}$ için $i-j$ arasında kat ettiğ i mesafe $d_{i j}=(a)+(b)+(c)+(d)$ eşittir.

(14) ve (15) numaralı kısıtların geçerliliği de Önerme 1 ve Önerme 2 yardımıyla gerçekleştirilebilir.

\section{DENEYSEL CALIŞMALAR (COMPUTATIONAL STUDIES)}

$\mathrm{Bu}$ bölümde önerilen matematiksel modelin etkinliğini test etmek amaciyla literatürden türetilen test problemleri üzerinde değişik performans kriterleri göz önüne alınarak değerlendirmeler gerçekleştirilmiştir.

\subsection{Deney Tasarımı (Experimental Design)}

Solomon'un 25 müşterilik test kümesi [29] ve Ichoua ve ark. [15] tarafindan kullanılan seyahat hızı matrisi göz önüne alınarak ZBARP için toplamda 56 tane yeni test problemi üretilmiştir. Solomon'un 25 müşterilik test kümesinde [29] müşteriler, 100x100'lük yüzey üzerinde değişik yerleşim parametrelerine göre yerleştirilmiştir. Altı farklı problem tipi tanımlanmıştır; $R_{1}, R_{2}, C_{1}, C_{2}, R C_{1}$ ve $R C_{2}$. Bu parametrelere göre $R$ tipi problemlerde müşteriler tamamen rassal, $C$ tipi problemlerde müşteriler belirli bölgelerde kümelenerek, $R C$ tipi problemlerde ise müşterilerin bir kısmı rassal kalan kısmı ise belirli bölgelerde kümelenerek yerleștirilmiştir. 1. tip problemlerde zaman penceresi genişliği küçük, 2. tip problemlerde ise zaman penceresi genişliği büyük tutulmuştur. Bir başka deyişle 1. tip problemlerde bir rotada hizmet verilen müşteri sayısı yaklaşık olarak 2 ile 5 arasındadır iken 2. tip problemlerde bir rotada hizmet verilen müşteri sayısı yaklaşık olarak 8-12 arasındadır. ZBARP için türetilen test problemlerinde, Solomon test kümesinde verilen, araç kapasitesi, müşteri talepleri, koordinatları ve servis zamanları üzerlerinde herhangi bir değişiklik yapılmadan doğrudan alınarak kullanılmıştır. Ichoua ve ark. [15] tarafindan kullanılan veriler de yine ayni şekilde doğrudan kullanılarak seyahat hızları düşük, orta ve yüksek hızda olmak üzere üç kategoride tanımlanmıştır. Bir iş günü üç zaman dilimine bölünmüş ve her zaman dilimine rassal olarak bir araç hız değeri atanmıştır.

Performans ölçütü olarak "Yüzde Sapma Değeri" (YSD) kullanılmıştır. Bu değer, matematiksel modelden elde edilen üst sinırın $\left(Z^{\ddot{U} S}\right)$, yine matematiksel modelden elde edilen alt sinırdan $\left(Z^{A S}\right)$ uzaklığını göstermektedir. Bu değer " 0 ”'a ne kadar yakın olursa elde edilen sonuç en iyi çözüme o kadar yakın olmaktadır. YSD değeri şu şekilde hesaplanmaktadır.

$$
Y S D=100 *\left(\frac{Z^{\mathrm{U} S}-Z^{A S}}{Z^{A S}}\right)
$$

Önerilen matematiksel model GAMS ara yüzünde kodlanmış ve matematiksel model çözücüsü olarak CPLEX 10.2 kullanılmıştır. Bütün koşumlarda çözücünün varsayılan parametre seviyeleri kullanılmıştır. Her bir koşum Intel Xeon 3.16 Ghz hızında $1 \mathrm{~GB}$ ara belleğe sahip, "Windows 7" işletim sistemi ile çalışan bilgisayarlarda gerçekleştirilmiştir. Bütün koşumlar 2 saat $(7200$ saniye $)$ ile sınırlandırılmıştır.

\subsection{Hesaplama Sonuçları (Computational Results)}

Tablo 1 'de $C_{1}, C_{2}, R_{1}, R_{2}, R C_{1}$ ve $R C_{2}$ tipi problemler için ortalama yüzde sapma değerleri verilmektedir (detaylı sonuçlar Ek-1'de verilmiştir). Bu sonuçlara göre, en fazla $R$ tipi problemlerde $(\% 69,03)$ en az ise $C$ tipi problemlerde $(\% 47,58)$ YSD elde edilmiștir. 56 test probleminin genel ortalamasinda ise \%61.86'l1k YSD elde edilmiştir. 3 tane $C_{1}, 2$ tane $C_{2}, 2$ tane $R_{1}$ ve 1 tane $R C_{1}$ olmak uzere toplamda 8 tane problem üzerinde eniyi çözüme ulaşılmıştır. En düşük ortalama YSD'nin, $C_{1}$ tipi problemlerde elde edilmesi, zaman pencerelerinin dar olduğu ve kümelenmiş olarak yerleşmiş müşterilerden oluşan problemlerin diğer problemlere göre daha kolay çözülebildiğini göstermektedir. Yerleşim parametrelerine göre bir karşılaştırma yapıldığında $R$ tipi problemlerden elde edilen ortalama YSD'nin $C$ ve $R C$ tipi problemlere göre yüksek olduğu gözlenmektedir.

$\mathrm{Bu}$ sonuçlara göre müşterilerin rassal olarak dağıldığ 1 problemlerin daha zor çözüldüğü görülmektedir. Her rotada az sayıda müşteriye hizmet verilebildiği 1. tip problemlerde, her rotada daha fazla sayıda müşteriye 
hizmet verilebildiği 2. tip problemlere göre daha düşük YSD'ler elde edilmesi, 1. tip problemlerin 2. tip problemlere göre zorluk derecesinin daha düşük olduğunun bir göstergesidir. Küçük boyutlu test problemleri üzerinde elde edilen ortalama YSD'lerin genel olarak yüksek olması ele alınan problemin zorluğunu kanıtlamaktadır. Önerilen matematiksel model göz önüne alınarak geliştirilebilecek metasezgisel algoritmalar veya dal-kesme gibi kesin algoritmalar, daha büyük boyutlu problemlerin kısa surelerde çözülmelerini, daha sıkı alt ve üst sınırların elde edilmesini ve daha düşük YSD değerlerine ulaşılmasını sağlayacaktır.

Tablo 1. Ortalama YSD (Average PDV)

\begin{tabular}{llll}
\hline Problem Adı & Üst Sınır & Alt Sınır & Ort. YSD \\
\hline$C 1$ & 417,26 & 216,21 & 45,17 \\
$C 2$ & 826,84 & 391,23 & 49,99 \\
$R 1$ & 729,36 & 417,32 & 49,09 \\
$R 2$ & 852,90 & 116,85 & 88,98 \\
$R C 1$ & 511,09 & 280,99 & 49,99 \\
$R C 2$ & 992,94 & 146,92 & 87,94 \\
\hline Ortalama & 721,73 & 261,59 & 61,86 \\
\hline
\end{tabular}

\subsection{Senaryo Analizleri (Scenario Analyses)}

Bu bölümde, geliştirilen matematiksel modelin çeşitli senaryolar altında nasıl sonuçlar verdiğini gözlemlemek için yapılan deneysel çalışmalar ve sonuçları sunulmuştur. Rassal olarak, her bir test problemi tipinden birer tane olmak üzere toplamda 6 problem seçilmiştir. Seçilen problemler: $C 102, C 203$, $R 105, R 202, R C 106$ ve $R C 201$ 'dir. Üç farklı senaryo altında toplamda 96 tane test problemi türetilmiştir.

\subsubsection{Senaryo 1-Talep değişiminin etkisi (Effect of the variation in demand)}

Birinci senaryo, müşteri talebindeki artış ve azalışların model üzerindeki etkisini göz önüne almaktadır. Müşteri talepleri 3 defa $\% 10$ oranında arttırılmış ve 3 defa $\% 10$ oranında azaltılmıştır. Toplamda 36 tane test problemi türetilmiş ve elde edilen ortalama YSD'ler Tablo 2'de sunulmuştur (detaylı sonuçlar Ek-2'de verilmiştir). Talebin azalması sapmaları arttırırken, diğer yandan talebin artışı da sapmaları arttırmakta ve problemlerin çözümünde en iyi sonuca daha uzun sürelerde varmaya sebep olmaktadır. Talepteki artış ve azalış, ortalamadan daha düşük değerler elde edilmesine neden olmuş, problemlerin daha kolay çözülebilmesini sağlamıştır.

Tablo 2. Senaryo 1 için YSD (Average PDV for Scenario 1)

\begin{tabular}{lllll}
\hline $\begin{array}{l}\text { Problem } \\
\text { Adı }\end{array}$ & Değişim & $\begin{array}{l}\text { Üst } \\
\text { Sınır }\end{array}$ & $\begin{array}{l}\text { Alt } \\
\text { Sınır }\end{array}$ & $\begin{array}{l}\text { Ort. } \\
\text { YSD }\end{array}$ \\
\hline S1_1 & $-\% 30$ & 910,58 & 363,58 & 50,72 \\
S1_2 & $-\% 20$ & 781,81 & 395,50 & 46,03 \\
S1_3 & $-\% 10$ & 778,50 & 399,11 & 45,59 \\
& $\% 0$ & 721,73 & 261,59 & 61,86 \\
S1_4 & $+\% 10$ & 805,83 & 389,98 & 50,90 \\
S1_5 & $+\% 20$ & 820,51 & 383,43 & 53,68 \\
S1_6 & $+\% 30$ & 841,38 & 390,26 & 53,45 \\
\hline
\end{tabular}

3.3.2. Senaryo 2-Araç kapasitesinin değişiminin etkisi (Effect of the variation in vehicle capacity)

İkinci senaryo, araç kapasitesindeki artış ve azalışların model üzerindeki etkisini göz önüne almaktadır. Araç kapasitesi 2 defa \%20 oranında arttırılmış ve 2 defa $\% 20$ oranında azaltılmış ve 24 tane test problemi türetilmiştir. Tablo 3'de Senaryo 2'den elde edilen ortalama YSD'leri sunulmaktadır (detaylı sonuçlar Ek-3'de verilmiştir). Sonuçlar incelendiği zaman, araç kapasitesinde değişiklik olmaksızın elde edilen ortalama YSD'nin $(\% 61,86), \quad$ kapasitesinin azalmasında olduğu gibi kapasitesinin artması ile elde edilenlerden daha yüksek olduğu gözlenmektedir. En düşük sapma, araç kapasitesi \%20 fazla olan araç filosunda elde edilmiştir. Müşteri taleplerinin karşılanması esnasında kullanılan araçların kapasitelerinin değişimi, problemin en iyi çözüme olan yakınlığını önemli derecelerde etkilemektedir.

Tablo 3. Senaryo 2 için YSD (Average PDV for Scenario 2)

\begin{tabular}{lllll}
\hline $\begin{array}{l}\text { Problem } \\
\text { Adı }\end{array}$ & Değişim & $\begin{array}{l}\text { Üst } \\
\text { Sinır }\end{array}$ & $\begin{array}{l}\text { Alt } \\
\text { Sınır }\end{array}$ & $\begin{array}{l}\text { Ort. } \\
\text { YSD }\end{array}$ \\
\hline S2_1 & $-\% 40$ & 922,33 & 388,04 & 57,63 \\
S2_2 & $-\% 20$ & 813,62 & 396,33 & 51,53 \\
& $\% 0$ & 721,73 & 261,59 & 61,86 \\
S2_3 & $+\% 20$ & 782,31 & 390,58 & 47,37 \\
S2_4 & $+\% 40$ & 1168,92 & 423,90 & 49,02 \\
\hline
\end{tabular}

3.3.3. Senaryo 3-Araç hızının değişiminin etkisi (Effect of the variation in vehicle speed)

Üçüncü senaryo, araç hızındaki artış ve azalışların model üzerindeki etkisini göz önüne almaktadır. Araç hızı 3 defa $\% 15$ oranında arttırılmış ve 3 defa $\% 15$ oranında azaltılmıştır. 36 tane test problemi türetilmiş ve ortalama YSD'ler Tablo 4'de sunulmuştur (detaylı sonuçlar Ek-4'de verilmiştir). Araç kapasitesinin azalmasında olduğu gibi 56 test probleminden elde edilen sapmaların $(\% 61,86)$ araç kapasitesinin artması ile elde edilenlerden daha yüksek olduğu gözlenmektedir. Trafik yoğunluğunun artıp azalmasına bağlı olarak araç hızında meydana gelen değişim, problemin en iyi çözüme olan yakınlığını önemli derecelerde etkilemektedir. Senaryo 3 'ten elde ettiğimiz deneysel sonuçlar göstermektedir ki, araç hızının \%45 azaldığı durumlarda en iyi çözüme daha çok yaklaşılmaktadır.

Tablo 4. Senaryo 3 için YSD (Average PDV for Scenario 3)

\begin{tabular}{lllll}
\hline Problem Adı & Değişim & Üst Sınır & Alt Sınır & YSD \\
\hline S3_1 & $-\% 45$ & 1151,98 & 810,35 & 33,00 \\
S3_2 & $-\% 30$ & 1018,60 & 616,78 & 39,33 \\
S3_3 & $-\% 15$ & 858,61 & 462,94 & 47,36 \\
& $\% 0$ & 721,73 & 261,59 & 61,86 \\
S3_4 & $+\% 15$ & 615,88 & 254,91 & 50,23 \\
S3_5 & $+\% 30$ & 678,89 & 324,67 & 47,80 \\
S3_6 & $+\% 45$ & 590,09 & 285,49 & 44,16 \\
\hline
\end{tabular}




\section{SONUÇ ve ÖNERILER (CONCLUSION and SUGGESTIONS)}

Bu çalışmada ARP'nin başka bir çeşidi olan ZBARP tanımlanmış ve bu problem için literatürdeki modellerden farklı bir şekilde ilk olarak, zamana bağ $l_{1}$ hız fonksiyonu özelliğini göz önüne alarak "ilk giren ilk çıkar (FIFO)" yaklaşımını sağlayan, doğrusal yapıya sahip ve kesin hesaplama gerçekleștiren yeni bir karma tam sayılı matematiksel model geliştirilmiştir.

Literatürden türetilen test problemleri çözülmüş ve sonuçları sunulmuştur. Solomon'un 25 müşterilik test kümesi [29] ve Ichoua ve ark. [15] tarafindan kullanılan seyahat hızı matrisi göz önüne alınarak ZBARP için yeni test problemleri üretilmiştir.

ZBARP, NP-Zor sinıfinda bir problem tipi olduğu için, orta ve büyük boyutlu problemlerde matematiksel modeller ile en iyi çözümlere ulaşmak mümkün değildir. $\mathrm{Bu}$ sebepten dolayı, gelecek çalışmalarda ilk olarak kısa sürelerde iyi çözümler elde edebilecek sezgisel veya meta-sezgisel bir yöntem geliştirilebilir. Bir sonraki aşamada ise eniyi çözümlere ulaşmak için bu çalıșmada önerdiğimiz matematiksel model, etkili bir sezgisel yöntem ve geçerli eşitsizlikleri kullanarak dal-kesme gibi kesin bir algoritma geliştirilebilir. Gelecek çalışmalarda ZBARP, heterojen araç filosunu göz önüne alacak şekilde genelleştirilebilir.

\section{TESSEKKÜR (ACKNOWLEDGEMENTS)}

$\mathrm{Bu}$ çalışma, Selçuk Üniversitesi Bilimsel Araştırma Projeleri Koordinatörlüğü (BAP) tarafindan 12101001 numaralı proje ile İsmail Karaoğlan danışmanlığında Çağrı Koç'un yüksek lisans tezi kapsamında desteklenmiştir. Sağlanan bu desteğe ve makalenin gelişmesine katkı sağlayan hakemlere değerli önerileri için teşekkürlerimizi sunuyoruz.

\section{KAYNAKLAR (REFERENCES)}

1. Toth, $P$. ve Vigo, D., The vehicle routing problem, Society for Industrial and Applied Mathematics (SIAM), Philadelphia, 2002.

2. Clark, G. Ve Wright J.W., "Scheduling of vehicles from a central depot to a number of delivery points", Operations Research, Cilt 12, 568-581, 1964.

3. Dantzig, G.B. ve Ramser, J.H., "The truck dispatching problem", Management Science, Cilt 6, 80-91, 1959.

4. Koç, Ç. ve Karaoğlan, İ., "Çok kullanımlı ve zaman pencereli araç rotalama problemi için bir matematiksel model", Journal of the Faculty of Engineering and Architecture of Gazi University, Cilt 27, No 3, 569-576, 2012.

5. Hezer, S. ve Kara, Y., "Eşzamanlı dağıtımlı ve toplamalı araç rotalama problemlerinin çözümü için bakteriyel besin arama optimizasyonu tabanlı bir algoritma", Journal of the Faculty of Engineering and Architecture of Gazi University, Cilt 28, No 2, 373-382, 2013.

6. Cordeau, J.-F., Laporte, G., Savelsbergh, M.W.P. ve Vigo, D., Vehicle routing. In: Barnhart, C., G. Laporte. (Eds.), Transportation, Handbooks in Operations Research and Management Science 14 367-428 (Chapter 6). Elsevier, Amsterdam, The Netherlands, 2007.

7. Golden, B.L., Raghavan, S. ve Wasil, E.A., The Vehicle Routing Problem: Latest Advances and Recent Challenges, Operations Research Computer Science Interfaces. Springer, New York, 2008.

8. Malandraki, C. ve Daskin, M.S., "Time dependent vehicle routing problems: Formulations, properties and heuristic algorithms", Transportation Science, Cilt 26, No 3, 185-200, 1992.

9. Ahn, B. H. ve Shin, J. Y., "Vehicle-routing with time windows and time-varying congestion", Journal of the Operational Research Society, Cilt 42, 393-400, 1991.

10. Hill, A.V. ve Benton, W.C., "Modelling intra-city time-dependent travel speeds for vehicle scheduling problems", Journal of the Operational Research Society, Cilt 43, No 4, 343-351, 1992.

11. Malandraki, C. ve Dial, R.B., "A restricted dynamic programming heuristic algorithm for the time dependent traveling salesman problem", European Journal of Operational Research, Cilt 90, No 1, 45-55, 1996.

12. Park, Y. B., "A solution of the bicriteria vehicle scheduling problems with time and area-depend travel speeds", Computers \& Industrial Engineering, Cilt 38, 173-187, 2000.

13. Jung, S. ve Haghani, A., "Genetic Algorithm for the Time-Dependent Vehicle Routing Problem", Transportation Research Record, Cilt 1771, 164-171, 2001.

14. Balseiro, S.R., Loiseau, I. ve Ramonet, J., "An ant colony algorithm hybridized with insertion heuristics for the time dependent vehicle routing problem with time windows", Computers \& Operations Research, Cilt 38, No 6, 954-966, 2011.

15. Ichoua, S., Gendreau, M. ve Potvin, J.Y., "Vehicle dispatching with time-dependent travel times", European Journal of Operational Research, Cilt 144, No 2, 379-396, 2003.

16. Fleischmann, B., Gietz, M. ve Gnutzmann, S., "Time-varying travel times in vehicle routing", Transportation Science, Cilt 38, No 2, 160-173, 2004.

17. Haghani, A. ve Jung, S., "A dynamic vehicle routing problem with time-dependent travel times", Computers \& Operations Research, Cilt 32, 2959-2986, 2005. 
18. Chen, H.K., Hsueh, C.F. ve Chang, M.S., "The real-time time-dependent vehicle routing problem", Transportation Research Part E, 42(5), 383-408, 2006.

19. Woensel, T. V., Kerbache, L., Peremans, H., ve Vandaele, N., "A queueing framework for routing problems with time-dependent travel times", Journal of Mathematical Modelling and Algorithms, Cilt 6, 151-173, 2007.

20. Woensel, T. V., Kerbache, L., Peremans, H., ve Vandaele, N., "Vehicle routing with dynamic travel times: A queueing approach", European Journal of Operational Research, Cilt 186, 990-1007, 2008.

21. Hashimoto, H., Yagiura, M. ve Ibaraki, T., "An iterated local search algorithm for the timedependent vehicle routing problem with time windows", Discrete Optimization, Cilt 5, No 2, 434-456, 2008.

22. Kuo, Y., Wang, C.C. ve Chuang, P.Y., "Optimizing goods assignment and the vehicle routing problem with time-dependent travel speeds", Computers \& Industrial Engineering, Cilt 57, No 4, 1385-1392, 2009.

23. Soler, D., Albiach, J. ve Martínez, E., "A way to optimally solve a time-dependent vehicle routing problem with time windows", Operations Research Letters, Cilt 37, No 1, 37-42, 2009.
24. Donati, A.V., Montemanni, R., Casagrande, N., Rizzoli, A.E. ve Gambardella, L.M., "Time dependent vehicle routing problem with a multi ant colony system", European Journal of Operational Research, Cilt 185, No 3, 1174 1191, 2008.

25. Jabali, O., Van Woensel, T., de Kok, A.G., Lecluyse, C. ve Peremans, H., "Time-dependent vehicle routing subject to time delay perturbations", IIE Transactions, Cilt 41, No 12, 1049-1066, 2009.

26. Kuo, Y., "Using simulated annealing to minimize fuel consumption for the time-dependent vehicle routing problem", Computers \& Industrial Engineering, Cilt 59, No 1, 157-165, 2010.

27. Figliozzi, M.A., "The impacts of congestion on time-definitive urban freight distribution networks $\mathrm{CO}_{2}$ emission levels: results from a case study in Portland, Oregon", Transportation Research Part C, Cilt 19, 766-778, 2011

28. Liu, Y., Chang, Q. ve Xiong, H., "An improved ant colony algorithm for the vehicle routing problem in time-dependent networks", IEICE Transactions on communications, Cilt 5, 15061510, 2011.

29. Solomon benchmark instances. http://web.cba.neu.edu/ msolomon/problems.htm. 2014.

\section{EKLER (APPENDICES)}

EK 1. $C$ tipi test problemlerinden elde edilen sonuçlar (Results obtained from $C$ type test problems)

\begin{tabular}{|c|c|c|c|c|c|c|c|c|c|}
\hline Problem & Üst Sınır & Alt Sınır & YSD & $\begin{array}{l}\text { Çözüm } \\
\text { Süresi } \\
\end{array}$ & Problem & Üst Sınır & Alt Sinır & YSD & $\begin{array}{l}\text { Çözüm } \\
\text { Süresi } \\
\end{array}$ \\
\hline$C 101$ & 379,71 & 379,71 & 0,00 & 5,65 & $C 201$ & 953,31 & 953,31 & 0,00 & 2,45 \\
\hline$C 102$ & 371,96 & 188,73 & 49,26 & 7200,00 & $C 202$ & 766,87 & 165,27 & 78,44 & 7200,00 \\
\hline$C 103$ & 526,56 & 73,13 & 86,11 & 7200,00 & $C 203$ & 906,49 & 9,99 & 98,89 & 7200,00 \\
\hline$C 104$ & 533,46 & 38,12 & 92,85 & 7200,00 & $C 204$ & 1133,68 & 0,39 & 99,96 & 7200,00 \\
\hline$C 105$ & 331,86 & 331,86 & $\mathbf{0 , 0 0}$ & 390,89 & $C 205$ & 773,44 & 773,44 & 0,00 & 265,00 \\
\hline$C 106$ & 511,46 & 511,46 & $\mathbf{0 , 0 0}$ & 138,06 & $C 206$ & 748,92 & 558,06 & 25,48 & 7200,00 \\
\hline$C 107$ & 318,11 & 257,43 & 19,07 & 7200,00 & $C 207$ & 633,08 & 475,07 & 24,95 & 7200,00 \\
\hline$C 108$ & 431,51 & 120,73 & 72,02 & 7200,00 & $C 208$ & 699,00 & 194,34 & 72,19 & 7200,00 \\
\hline$C 109$ & 350,71 & 44,73 & 87,24 & 7200,00 & & & & & \\
\hline
\end{tabular}

EK 2. $R$ tipi test problemlerinden elde edilen sonuçlar (Results obtained from $R$ type test problems)

\begin{tabular}{|c|c|c|c|c|c|c|c|c|c|}
\hline Problem & Üst Sınır & Alt Sınır & YSD & $\begin{array}{l}\text { Çözüm } \\
\text { Süresi }\end{array}$ & Problem & Üst Sınır & Alt Sinır & YSD & $\begin{array}{l}\text { Çözüm } \\
\text { Süresi }\end{array}$ \\
\hline$R 101$ & 1277,25 & 1277,25 & 0,00 & 4,04 & $R 201$ & 1089,93 & 935,78 & 14,14 & 7200,00 \\
\hline$R 102$ & 979,67 & 780,43 & 20,33 & 7200,00 & $R 202$ & 1173,6 & 212,28 & 81,91 & 7200,00 \\
\hline$R 103$ & 636,13 & 372,27 & 41,47 & 7200,00 & $R 203$ & 1176,48 & 0,13 & 99,98 & 7200,00 \\
\hline$R 104$ & 537,29 & 188,79 & 64,86 & 7200,00 & $R 204$ & 729,85 & 5,88 & 99,19 & 7200,00 \\
\hline$R 105$ & 864,55 & 864,55 & 0,00 & 780,44 & $R 205$ & 734,78 & 58,32 & 92,06 & 7200,00 \\
\hline$R 106$ & 656,74 & 455,18 & 30,69 & 7200,00 & $R 206$ & 668,91 & 0,89 & 99,86 & 7200,00 \\
\hline$R 107$ & 612,95 & 217,55 & 64,50 & 7200,00 & $R 207$ & 727,2 & 0,09 & 99,98 & 7200,00 \\
\hline$R 108$ & 684,28 & 125,41 & 81,67 & 7200,00 & $R 208$ & 671,86 & 0,07 & 99,98 & 7200,00 \\
\hline$R 109$ & 642,96 & 332,04 & 48,35 & 7200,00 & $R 209$ & 727,41 & 10,25 & 98,59 & 7200,00 \\
\hline$R 110$ & 641,29 & 170,61 & 73,39 & 7200,00 & $R 210$ & 888,02 & 61,63 & 93,05 & 7200,00 \\
\hline$R 111$ & 619,63 & 218,55 & 64,72 & 7200,00 & $R 211$ & 793,92 & 0,09 & 99,98 & 7200,00 \\
\hline$R 112$ & 599,64 & 5,21 & 99,13 & 7200,00 & & & & & \\
\hline
\end{tabular}


EK 3. $R C$ tipi test problemlerinden elde edilen sonuçlar (Results obtained from $R C$ type test problems)

\begin{tabular}{|c|c|c|c|c|c|c|c|c|c|}
\hline Problem & Üst Sınır & Alt Sinır & YSD & $\begin{array}{l}\text { Çözüm } \\
\text { Süresi }\end{array}$ & Problem & Üst Sınır & Alt Sınır & YSD & $\begin{array}{l}\text { Çözüm } \\
\text { Süresi }\end{array}$ \\
\hline$R C 101$ & 637,24 & 637,24 & $\mathbf{0 , 0 0}$ & 133,98 & $R C 201$ & 1257,88 & 669,74 & 46,75 & 7200,00 \\
\hline$R C 102$ & 531,44 & 412,54 & 22,37 & 7200,00 & $R C 202$ & 1320,96 & 173,77 & 86,84 & 7200,00 \\
\hline$R C 103$ & 380,1 & 197,13 & 48,13 & 7200,00 & $R C 203$ & 1008,49 & 4,22 & 99,58 & 7200,00 \\
\hline$R C 104$ & 495,79 & 88,83 & 82,08 & 7200,00 & $R C 204$ & 660,53 & 1,71 & 99,74 & 7200,00 \\
\hline$R C 105$ & 707,14 & 548,48 & 22,43 & 7200,00 & $R C 205$ & 1144,15 & 279,1 & 75,60 & 7200,00 \\
\hline$R C 106$ & 486,8 & 307,03 & 36,92 & 7200,00 & $R C 206$ & 945,75 & 44,24 & 95,32 & 7200,00 \\
\hline$R C 107$ & 476,53 & 55,02 & 88,45 & 7200,00 & $R C 207$ & 878,45 & 2,55 & 99,70 & 7200,00 \\
\hline$R C 108$ & 373,72 & 1,66 & 99,55 & 7200,00 & $R C 208$ & 727,34 & 0,08 & 99,98 & 7200,00 \\
\hline
\end{tabular}

EK 4. Senaryo 1'den elde edilen sonuçlar (Results obtained from Scenario 1)

\begin{tabular}{|c|c|c|c|c|c|c|c|c|c|c|c|}
\hline $\begin{array}{l}\text { Talep } \\
\text { Değişimi }\end{array}$ & Problem & $\begin{array}{l}\text { Üst } \\
\text { Sınır }\end{array}$ & $\begin{array}{l}\text { Alt } \\
\text { Sinır }\end{array}$ & YSD & $\begin{array}{l}\text { Çözüm } \\
\text { Süresi } \\
\end{array}$ & $\begin{array}{l}\text { Talep } \\
\text { Değişimi }\end{array}$ & Problem & $\begin{array}{l}\text { Üst } \\
\text { Sınır }\end{array}$ & $\begin{array}{l}\text { Alt } \\
\text { Sinır } \\
\end{array}$ & YSD & $\begin{array}{l}\text { Çözüm } \\
\text { Süresi }\end{array}$ \\
\hline \multirow[t]{6}{*}{$-\% 30$} & S1_1_C102 & 282,05 & 116,27 & 58,77 & 7200,00 & \multirow[t]{6}{*}{$+\% 10$} & S1_4_C102 & 352,26 & 127,78 & 63,72 & 7200,00 \\
\hline & S1_1_C203 & 1506,30 & 19,05 & 98,73 & 7200,00 & & S1_4_C203 & 749,96 & 17,55 & 97,65 & 7200,00 \\
\hline & S1_1_R105 & 764,87 & 764,87 & 0,00 & 147,59 & & S1_4_R105 & 764,87 & 764,87 & 0,00 & 38,38 \\
\hline & S1_1_R202 & 1124,35 & 216,37 & 80,75 & 7200,00 & & $\mathrm{~S} 1 \_4-\mathrm{R} 202$ & 1108,07 & 233,67 & 78,91 & 7200,00 \\
\hline & S1_1_RC106 & 400,08 & 321,03 & 19,75 & 7200,00 & & $\mathrm{~S} 1$-4_RC106 & 474,01 & 349,93 & 26,17 & 7200,00 \\
\hline & S1_1_RC201 & 1385,85 & 743,92 & 46,32 & 7200,00 & & $\mathrm{~S} 1 \_4 \_\mathrm{RC} 201$ & 1385,85 & 846,10 & 38,94 & 7200,00 \\
\hline \multirow[t]{6}{*}{$-\% 20$} & S1_2_C102 & 282,05 & 115,27 & 59,13 & 7200,00 & \multirow[t]{6}{*}{$+\% 20$} & S1_5_C102 & 375,78 & 122,64 & 67,36 & 7200,00 \\
\hline & $\mathrm{S} 1{ }^{-} 2-\mathrm{C} 203$ & 749,96 & 18,52 & 97,53 & 7200,00 & & $\mathrm{~S} 1$-5_C203 & 749,95 & 19,25 & 97,43 & 7200,00 \\
\hline & S1_2_R105 & 764,87 & 764,87 & 0,00 & 31,61 & & $\mathrm{~S} 1$ 5_R 105 & 764,87 & 764,87 & 0,00 & 7200,00 \\
\hline & S1_2_R202 & 1110,48 & 246,77 & 77,77 & 7200,00 & & $\mathrm{~S} 1 \_5[\mathrm{R} 202$ & 1110,48 & 259,37 & 76,64 & 7200,00 \\
\hline & $\mathrm{S} 1 \_2 \_\mathrm{RC} 106$ & 397,70 & 388,4 & 2,33 & 7200,00 & & $\mathrm{~S} 1$-5_RC106 & 536,15 & 327,80 & 38,86 & 7200,00 \\
\hline & S1_2_RC201 & 1385,85 & 839,18 & 39,44 & 7200,00 & & $\mathrm{~S} 1$ 5_RC201 & 1385,85 & 806,68 & 41,79 & 7200,00 \\
\hline \multirow[t]{6}{*}{$-\% 10$} & S1_3_C102 & 268,63 & 121,28 & 54,85 & 7200,00 & \multirow[t]{6}{*}{$+\% 30$} & S1_6_C102 & 402,10 & 120,34 & 70,07 & 7200,00 \\
\hline & $\mathrm{S} 1 \_3 \_\mathrm{C} 203$ & 749,95 & 18,84 & 97,48 & 7200,00 & & S1_6_C203 & 849,54 & 19,22 & 97,73 & 7200,00 \\
\hline & S1_3_R105 & 764,87 & 764,87 & 0,00 & 20,37 & & S1_6_R105 & 764,87 & 764,87 & 0,00 & 25,77 \\
\hline & S1_3_R202 & 1104,00 & 250,52 & 77,3 & 7200,00 & & S1_6_R202 & 1108,07 & 237,92 & 78,52 & 7200,00 \\
\hline & $\mathrm{S} 1$-3_RC106 & 397,70 & 371,95 & 6,47 & 7200,00 & & $\mathrm{~S} 1 \_6 \_\mathrm{RC} 106$ & 537,85 & 343,22 & 36,18 & 7200,00 \\
\hline & $\mathrm{S} 1$-3_RC201 & 1385,85 & 867,23 & 37,42 & 7200,00 & & $\mathrm{~S} 1 \_6 \_\mathrm{RC} 201$ & 1385,85 & 856,02 & 38,23 & 7200,00 \\
\hline
\end{tabular}

EK 5. Senaryo 2'den elde edilen sonuçlar (Results obtained from Scenario 2)

\begin{tabular}{|c|c|c|c|c|c|c|c|c|c|c|c|}
\hline $\begin{array}{l}\text { Kapasite } \\
\text { Değişimi }\end{array}$ & Problem & $\begin{array}{l}\text { Üst } \\
\text { Sinır }\end{array}$ & $\begin{array}{l}\text { Alt } \\
\text { Sinır } \\
\end{array}$ & YSD & $\begin{array}{l}\text { Çözüm } \\
\text { Süresi } \\
\end{array}$ & $\begin{array}{l}\text { Kapasite } \\
\text { Değişimi }\end{array}$ & Problem & $\begin{array}{l}\text { Üst } \\
\text { Sınır }\end{array}$ & $\begin{array}{l}\text { Alt } \\
\text { Sinır }\end{array}$ & YSD & $\begin{array}{l}\text { Çözüm } \\
\text { Süresi } \\
\end{array}$ \\
\hline \multirow[t]{6}{*}{$-\% 40$} & S2_1_C102 & 667,51 & 125,50 & 81,19 & 7200,00 & \multirow[t]{6}{*}{$+\% 40$} & S2_4_C102 & 312,78 & 122,23 & 60,92 & 7200,00 \\
\hline & S2_1_C203 & 953,11 & 18,87 & 98,02 & 7200,00 & & $\mathrm{~S} 2$-4_C203 & 749,94 & 20,78 & 97,22 & 7200,00 \\
\hline & S2_1_R105 & 764,87 & 764,87 & 0,00 & 31,64 & & $\mathrm{~S} 2$-4_R105 & 764,87 & 764,87 & 0,00 & 43,72 \\
\hline & $\mathrm{S} 2 \_1$ R202 & 1106,70 & 268,63 & 75,72 & 7200,00 & & $\mathrm{~S} 2$-4_R202 & 3402,41 & 426,97 & 87,45 & 7200,00 \\
\hline & S2_1_RC106 & 655,95 & 325,15 & 50,43 & 7200,00 & & $\mathrm{~S} 2 \_4 \_\mathrm{RC} 106$ & 397,70 & 358,41 & 9,87 & 7200,00 \\
\hline & $\mathrm{S} 2$ 1_RC201 & 1385,85 & 825,26 & 40,45 & 7200,00 & & $\mathrm{~S} 2{ }^{-} 4 \_\mathrm{RC} 201$ & 1385,85 & 850,18 & 38,65 & 7200,00 \\
\hline \multirow[t]{6}{*}{$-\% 20$} & S2_2_C102 & 326,65 & 126,89 & 61,15 & 7200,00 & \multirow[t]{6}{*}{$+\% 20$} & S2_3_C102 & 291,49 & 125,05 & 57,09 & 7200,00 \\
\hline & $\mathrm{S} 2 \_2 \_\mathrm{C} 203$ & 749,95 & 20,56 & 97,25 & 7200,00 & & S2_3_C203 & 749,95 & 20,29 & 97,29 & 7200,00 \\
\hline & S2_2_R 105 & 764,87 & 764,87 & 0,00 & 50,63 & & $\mathrm{~S} 2 \_3 \_\mathrm{R} 105$ & 764,87 & 764,87 & 0,00 & 26,86 \\
\hline & $\mathrm{S} 2 \_2-\mathrm{R} 202$ & 1110,48 & 239,30 & 78,45 & 7200,00 & & $\mathrm{~S} 2 \_3 \_\mathrm{R} 202$ & 11040 & 236,18 & 78,60 & 7200,00 \\
\hline & $\mathrm{S} 2 \_2 \_\mathrm{RC} 106$ & 543,96 & 350,92 & 35,48 & 7200,00 & & $\mathrm{~S} 2 \_3 \_\mathrm{RC} 106$ & 397,70 & 347,84 & 12,53 & 7200,00 \\
\hline & $\mathrm{S} 2 \_2 \_\mathrm{RC} 201$ & 1385,85 & 875,45 & 36,82 & 7200,00 & & $\mathrm{~S} 2 \_3 \_\mathrm{RC} 201$ & 1385,85 & 849,25 & 38,71 & 7200,00 \\
\hline
\end{tabular}

EK 6. Senaryo 3'den elde edilen sonuçlar (Results obtained from Scenario 3)

\begin{tabular}{|c|c|c|c|c|c|c|c|c|c|c|c|}
\hline $\begin{array}{l}\text { Hız } \\
\text { Değişimi }\end{array}$ & Problem & $\begin{array}{l}\text { Üst } \\
\text { Sinır }\end{array}$ & $\begin{array}{l}\text { Alt } \\
\text { Sinır }\end{array}$ & YSD & $\begin{array}{l}\text { Çözüm } \\
\text { Süresi }\end{array}$ & $\begin{array}{l}\text { Hız } \\
\text { Değişimi }\end{array}$ & Problem & $\begin{array}{l}\text { Üst } \\
\text { Sınır }\end{array}$ & $\begin{array}{l}\text { Alt } \\
\text { Sinur }\end{array}$ & YSD & $\begin{array}{l}\text { Çözüm } \\
\text { Süresi } \\
\end{array}$ \\
\hline \multirow[t]{6}{*}{$-\% 45$} & S3_1_C102 & 599,33 & 369,28 & 38,38 & 7200,00 & \multirow[t]{6}{*}{$+\% 15$} & S3_4_C102 & 271,76 & 135,67 & 50,07 & 7200,00 \\
\hline & S3_1_C203 & 924,61 & 29,17 & 96,84 & 7200,00 & & S3_4_C203 & 744,45 & 15,39 & 97,93 & 7200,00 \\
\hline & S3_1_R105 & 1349,23 & 1349,23 & 0,00 & 6,09 & & S3_4_R105 & 638,02 & 638,02 & 0,00 & 203,49 \\
\hline & S3_1_R202 & 1459,10 & 605,70 & 58,48 & 7200,00 & & $\mathrm{~S} 3$ _4_R202 & 1066,67 & 208,41 & 80,46 & 7200,00 \\
\hline & S3_1_RC106 & 934,51 & 934,51 & 0,00 & 6153,30 & & $\mathrm{~S} 3{ }^{-} 4$ 4_RC106 & 358,52 & 277,06 & 22,72 & 7200,00 \\
\hline & $\mathrm{S} 3$ 1_RC201 & 1645,11 & 1574,23 & 4,308 & 7200,00 & & $\mathrm{~S} 3$ _4_RC201 & 1326,17 & 716,46 & 45,97 & 7200,00 \\
\hline \multirow[t]{6}{*}{$-\% 30$} & S3_2_C102 & 481,00 & 319,26 & 33,62 & 7200,00 & \multirow[t]{6}{*}{$+\% 30$} & S3_5_C102 & 300,95 & 127,81 & 57,53 & 7200,00 \\
\hline & S3_2_C203 & 871,69 & 32,51 & 96,27 & 7200,00 & & S3_5_C203 & 746,70 & 15,08 & 97,98 & 7200,00 \\
\hline & S3_2_R105 & 1242,08 & 1242,08 & 0,00 & 37,28 & & S3_5_R105 & 650,45 & 650,45 & 0,00 & 1169,89 \\
\hline & S3_2_R202 & 1380,71 & 404,61 & 70,69 & 7200,00 & & S3_5_R202 & 1060,62 & 182,86 & 82,75 & 7200,00 \\
\hline & S3_2_RC106 & 733,89 & 664,60 & 9,44 & 7200,00 & & $\mathrm{~S} 3{ }^{-} 5$ - $\mathrm{RC} 106$ & 380,15 & 304,06 & 20,01 & 7200,00 \\
\hline & $\mathrm{S} 3$ 2_RC201 & 1402,23 & 1037,66 & 25,99 & 7200,00 & & $\mathrm{~S} 3$ 5_RC201 & 934,47 & 667,81 & 28,53 & 7200,00 \\
\hline \multirow[t]{6}{*}{$-\% 15$} & S3_3_C102 & 358,46 & 145,99 & 59,27 & 7200,00 & \multirow[t]{6}{*}{$+\% 45$} & S3_6_C102 & 245,69 & 109,87 & 55,28 & 7200,00 \\
\hline & S3_3_C203 & 792,44 & 32,66 & 95,87 & 7200,00 & & S3_6_C203 & 743,39 & 6,20 & 99,16 & 7200,00 \\
\hline & S3_3_R105 & 930,01 & 930,01 & 0,00 & 496,52 & & S3_6_R105 & 591,55 & 591,55 & 0,00 & 2878,30 \\
\hline & S3_3_R202 & 1114,96 & 284,43 & 74,48 & 7200,00 & & S3_6_R202 & 1045,87 & 176,91 & 83,08 & 7200,00 \\
\hline & $\mathrm{S} 3$ 33_RC106 & 626,50 & 489,61 & 21,84 & 7200,00 & & S3_6_RC106 & 311,59 & 225,97 & 27,47 & 7200,00 \\
\hline & S3_3_RC201 & 1329,33 & 894,98 & 32,67 & 7200,00 & & $\mathrm{~S} 3 \_6 \_\mathrm{RC} 201$ & 602,48 & 602,48 & 0,00 & 3389,50 \\
\hline
\end{tabular}

